\title{
EDUCAÇÃO E CONTRADIÇÃO: IMPLICAÇÕES TEORICO- PRÁTICAS NA FORMAÇÃO DOCENTE
}

Roseli Gall do Amaral da Silva, Stela Galbardi de Resende.

Universidade Tecnológica Federal do Paraná - UTFPR, Apucarana-PR. E-mail: amararoseli@gmail.com

\section{RESUMO}

O objetivo deste trabalho de pesquisa é abordar a contribuição de Marx e Engels no que concerne a elaboração da questão teoria e prática e suas implicações para educação, na obra "A Ideologia Alemã". Os autores apresentam uma análise da história pelo viés do método materialismo histórico, partindo da produção material para a compreensão das relações sociais, suas condições de existência e a inserção da educação neste processo. Como instrumento de luta, a educação, segundo os autores, configura-se em dois momentos: um de crítica a ideologia burguesa e outro de formulação de uma nova concepção de mundo com vistas aos interesses populares. Ao pensar as construções históricas a partir da produção material (trabalho), Marx e Engels, expressaram não somente um método de análise, mas também apontaram caminhos que muito contribuem ainda hoje, para as reflexões acerca das questões educacionais e suas contradições no que diz respeito a sua instrumentalização.

Palavras-chave: Educação, trabalho, práxis, materialismo histórico.

\section{EDUCATION AND CONTRADICTION: THEORETICAL-PRACTICAL IMPLICATIONS IN TEACHING TRAINING}

\begin{abstract}
The objective of this research is to discuss the contribution of Marx and Engels in the elaboration of the question theory and practice and its implications for education in "The German Ideology". Starting the division of labor, the authors present an analysis of history through the bias of the method of historical materialism, starting from material production for the understanding of social relations, their conditions of existence and the insertion of education in this process. As an instrument of struggle, education, according to the authors, consists of two moments: one of criticism of bourgeois ideology and the other of formulating a new conception of the world with a view to popular interests. In thinking about historical constructions from material production, Marx and Engels expressed besides method of analysis, also pointed to paths that still contribute a great deal today to reflections on educational issues and their contradictions regarding their instrumentalization.
\end{abstract}

Keywords: Education, work, praxis, historical materialism. 


\section{INTRODUÇÃO}

As discussões a respeito da questão teoria e prática no que se refere à formação educacional tem sido tema das preocupações da contemporaneidade. Para as ciências sociais, uma teoria desligada da prática não chega se quer a ser uma teoria. Nesse sentido, o critério da verdade teórica é a prática. A separação entre ambas, segundo Pedro Demo, está diretamente ligada ao processo de alienação, emergente do processo dual que separou o trabalho em manual e intelectual.

Para uma melhor compreensão da construção social desta discussão utilizaremos a obra "A ideologia Alemã" de Marx e Engels, escrita em 1845-1846, no refúgio em Bruxelas, depois de sua expulsão do território francês, pelo ministro da França Guizot. Constando de dois volumes, o primeiro contém a crítica da filosofia pós-hegeliana e o segundo a crítica do "socialismo verdadeiro". Nos deteremos ao capítulo I do volume I que por ter significado independente, abrange o conteúdo fundamental de toda a obra, pela sua exposição da concepção materialista da história e pelo desvelar de categorias que permitem a compreensão das relações sociais a partir das relações de produção, numa conexão objetiva entre forças produtivas e relações sociais.

A obra representa, segundo Artur Giannotti, em "Os Pensadores" um balanço da consciência filosófica dos autores onde rompem com o pensamento de Feurbach. O objetivo principal da obra é tecer uma crítica profunda da ideologia burguesa e do materialismo pré-marxista, a partir das posições da classe operária e da necessidade da formação de uma ideologia dessa mesma classe. Para isto, logo no prefácio já são questionadas as formas falsas como os homens representam a si próprios e a vida, e a intenção dos autores em libertá-los dessas ficções:

Libertemo-los da ficção do cérebro, das idéias, dos dogmas, das essências imaginadas sob cujo jugo se atrofiam. Rebelem-nos contra o domínio das idéias. Ensinemo-los a trocar estas fantasias por idéias que correspondem à essência do Homem [...] a terem uma atitude crítica face a elas, [...] a expulsá-las da cabeça, [...] e a realidade vigente ruirá (MARX, 1984, p.7).

No texto, subentende-se que o ensino é a forma pela qual os autores propõem que seja construída essa libertação, o que nos remete ao conceito de educação que fundamenta seus pressupostos: o conhecimento como instrumento que permita desmascarar no processo histórico as relações sociais como construto humano e, portanto, cabível de interferências e mudanças. Entretanto, é ilusório pensar que a educação seja capaz por si só de transformar o mundo, o que fica estabelecido é que a educação deve ser um instrumento e que existem tarefas para os educadores como desmistificação da alienação e da ideologia, ou seja, a conscientização da classe oprimida.

Segundo Dermeval Saviani, na obra "Escola e Democracia" (1995), a escola não é e nem pode ser vista como redentora da humanidade, e, portanto, não pode ser responsabilizada pela mudança da sociedade, justamente porque é uma instituição determinada pela estrutura social e não uma determinante. A educação é um instrumento social que em cada período histórico busca transformar e moldar o comportamento humano. Logo, modifica-se a cada período a fim de atender as necessidades históricas. Dentro desta perspectiva, toda postura revolucionária é essencialmente histórica, porque se coloca na direção do desenvolvimento da história, implicando nos interesses do novo coincidirem com os interesses da transformação. (SAVIANI,1995, p.50).

É nesse sentido que a questão teoria e prática levantada na obra "A Ideologia alemã", é atual e relevante, pois está diretamente ligada a questão educacional no que diz respeito a concepção de educação e aos conteúdos por ela transmitidos.

\section{METODOLOGIA}

Para a construção da pesquisa utilizou-se um levantamento bibliográfico e documental com abordagem qualitativa. A pesquisa bibliográfica realizada permitiu melhor situar o tema e as reflexões teóricas que problematizam e compreendem as implicações teorico-práticas na formação docente. 


\section{RESULTADOS}

Algumas categorias são fundamentais, segundo Marx, para a compreensão de como se organizam e estruturam as construções humanas: o conceito de homem, de história e de trabalho. A primeira premissa que norteia a exposição da obra é a concepção de homem como ser concreto e situado, portanto como ser histórico. A esse respeito, Erich Fromm, na obra "Conceito Marxista de Homem" (1979), enfatiza que o problema central enfocado por Marx é o da existência do homem individual real, que é aquilo que ele faz, e cuja "natureza", desabrocha e se revela na história. Segundo Fromm, Marx vê o homem em sua plena realidade como membro de uma dada sociedade e de uma dada classe, auxiliado em seu desenvolvimento pela sociedade, e ao mesmo tempo prisioneiro desta. Assim como Saviani, Erich Fromm, interpreta o pressuposto marxista a respeito da realização total da humanidade do homem e de sua emancipação das forças que o aprisionam vinculado ao reconhecimento dessas forças e a mudança social baseada em tal reconhecimento. A filosofia de Marx, antes de tudo, representa um protesto contra a alienação do homem: "contra sua perda de si mesmo e contra sua transformação em objeto; é um movimento oposto à desumanização e automatização do homem, inerente à evolução do capitalismo industrial ocidental" (Fromm, 1979, p.09).

Segundo Fromm, Marx tece críticas implacáveis para com todas as "soluções" para o problema da existência humana que tentam apresentar propostas negando ou mascarando as dicotomias intrínsecas da existência do homem. Em essência Marx preocupou-se em desvelar o potencial humano e sua relação com o capital. A consciência, segundo Marx, nunca pode ser outra coisa senão o ser consciente, e o ser dos homens é o seu processo real de vida. E em toda ideologia os homens e as suas relações aparecem de cabeça para baixo como numa Câmera obscura (MARX, 1984, p.22).

Neste trecho, Marx e Engels focalizam a História como instrumento que permite desvendar as contradições inerentes ao processo de construção da vida. Em contraposição ao idealismo de Hegel que parte do mundo das ideias, das construções que descem do "céu a terra", isto é, não se parte daquilo que os homens dizem, imaginam ou representam. Não se investigam os homens narrados, pensados e imaginados para então se compreender aos homens de carne e osso. Em sua análise, Marx e Engels partem dos homens realmente ativos, e com base no seu processo real de vida apresentam-se o desenvolvimento dos reflexos e ecos ideológicos deste processo de vida. (Marx, 1984). Ao apresentar a concepção materialista da história, Marx, explica as formações das ideias a partir da práxis material e a necessidade de se estabelecer relações entre as construções históricas e a produção material da vida a partir do trabalho.

Uma das principais forças da História apresentada por Marx foi à divisão do trabalho. Assim que o trabalho começa a ser distribuído, cada homem tem um círculo de atividade determinado e exclusivo que lhe é imposto e do qual não pode sair. Mas, segundo Marx, a divisão do trabalho só se torna realmente divisão a partir do momento em que surge uma divisão do trabalho material e intelectual. (MARX, 1984, p.34). Com a divisão do trabalho, nesse nível, está dada a possibilidade de mascarar as contradições inerentes à relação de força de produção, estado de sociedade e a consciência. E é precisamente por esta contradição do interesse particular e do interesse comunitário que as classes se desenvolvem:

[...] o interesse comunitário assume uma forma autônoma como Estado, separado dos interesses reais dos indivíduos e do todo, e ao mesmo tempo como comunidade ilusória, mas sempre sobre a base real dos laços existentes (famílias, tribos, língua) [...] de divisão do trabalho em uma escala maior, e demais interesses, e especialmente, das classes desde logo condicionadas pela divisão do trabalho e que se diferenciam em todas essas massas de homens, e das quais uma domina todas as outras (Marx, 1984, p.37). 
Essa comunidade ilusória, descrita por Marx, que se estabelece como classe dominante, na verdade segundo o autor é a classe que tem o poder material ou, os meios de produção. A classe que tem a sua disposição os meios para a produção material dispõe assim, ao mesmo tempo, dos meios para a produção intelectual. Pelo que, lhe estão assim, ao mesmo tempo submetidas à construção das ideias dominantes. "As idéias dominantes não são mais do que a expressão ideal das relações materiais dominantes, as relações materiais dominantes concebidas como ideias. Portanto, as relações que precisamente tornam uma classe dominante são as idéias do seu domínio" (Marx, 1984, p. 56).

Um processo hegemônico precisa de intelectuais que o sustentem, para validar um movimento necessita-se de estrutura, e essa apropriação é feita através da cultura (GRAMSCl, 2000). A classe dominada sem conseguir organizar sua própria visão de mundo permanece desestruturada e passiva. Foi com este objetivo que Marx e Engels escrevem a obra "A Ideologia Alemã", buscando habilitar a classe proletária com instrumentos necessários para elaborarem de forma coerente e crítica a consciência de classe. Para tomar consciência da alienação a que está submetida, a classe operária precisa perceber que age sob os valores impostos pela classe dominante. Para isso, segundo Sánchez Vázquez, na obra "Filosofia da Práxis" (1977), faz-se necessário que o homem domine o processo histórico sendo capaz de compreendê-lo pela práxis, categoria central da filosofia que se concebe não só como interpretação do mundo, mas como guia de sua transformação.

É pela práxis, que o homem transforma o mundo ao mesmo tempo em que também é transformado, e o trabalho é a expressão concreta da práxis. A práxis, é a atividade material do homem social. O homem é um ser social e histórico, ou seja, encontra-se imbricado numa rede de relações sociais e enraizado num determinado terreno histórico, e segundo Vásquez: "[...] Nunca se enfrenta um fato puro, os fatos estão sempre integrados numa determinada perspectiva ideológica, que os engendra e condiciona social e historicamente, nutrindo-os de valores e juízos" (VÁSQUEZ, 1977, p. 09). Criando um ambiente histórico, nos quais os homens adotam inconscientemente pontos de vistas e reflexões práticas. Nas Teses sobre Feuerbach, Marx explicita:

A questão de saber se o pensamento humano pertence a verdade objetiva não é uma questão da teoria, mas uma questão prática. É na práxis que o homem tem de comprovar a verdade, Isto é, a realidade e o poder, o caráter terreno, do seu pensamento (MARX, 1984, p. 107-8).

A contribuição de Marx e Engels nesse sentido constitui-se na concepção histórica e dialética do real, A teoria marxista, ou materialismo histórico, também chamado por Gramsci de "filosofia da práxis", parte do movimento como parte fundamental da matéria e existe independente da consciência; portanto, a consciência é reflexo da produção material. Segundo Saviani (2003), A concepção dialética expressa no materialismo histórico procura compreender e explicar o todo, abrangendo desde a forma como são produzidas as relações sociais e suas condições de existência até a inserção da educação nesse processo. Sobre a questão educacional, Marx expõem:

A doutrina materialista da transformação das circunstâncias e da educação esquece que as circunstâncias têm de ser transformadas pelos homens e que o próprio educador tem que ser educado. Daí que ela tenha de cindir a sociedade em duas partes - uma das quais fica elevada acima dela. A coincidência da mudança das circunstâncias e da atividade humana ou da autotransformação só pode ser tomada e racionalmente entendida como práxis revolucionária (MARX, 1984, p.108).

Um dos primeiros obstáculos que a educação tem que superar é a separação entre concreto e abstrato. O pensamento parte do empírico, mas, tem como suporte o real concreto, pode-se dizer que o concreto-ponto de partida é o concreto real e o concreto-ponto de chegada é o concreto pensado, isto é, a teoria é a apropriação pelo pensamento do real-concreto, e quem a domina impõe pela ideologia a sua visão de mundo. Assim, o verdadeiro ponto de partida, bem como 
ponto de chegada é o concreto real. E, o concreto é histórico, ele se dá e se revela pela práxis. Em uma prática fundamentada teoricamente, se a teoria desvinculada da prática se configura como contemplação, a prática desvinculada da teoria é puro espontaneísmo (SAVIANI, 2003, p. 141).

Neste sentido, a filosofia da práxis é um movimento prioritariamente prático que se fundamenta teoricamente, fortalece-se na teoria para esclarecer o sentido, dar direção à prática. $E$, a prática tem primado pela teoria por ser ela que a origina (SAVIANI, 2003, p. 142).

\section{DISCUSSÃO}

Segundo Gramsci, a principal tarefa da Filosofia da Práxis, ou do materialismo histórico, é desvendar o conhecimento a todas as classes, levando-as do senso comum ao pensamento filosófico. Gramsci discute a questão teoria-prática, (ou a divisão entre trabalho manual e intelectual) levantando a dualidade educacional, onde elite e classes operárias são tratadas de formas diferentes. A esse respeito, Saviani (2003), levanta a questão do saber sistematizado ser propriedade privada a serviço do grupo dominante, e estabelece a diferença entre a produção do saber e a sistematização do saber. A produção do saber é social, logo, ocorre no interior das relações sociais. A elaboração do saber implica expressar de forma sistematizada o saber que surge da prática social. Essa expressão elaborada supõe o domínio dos instrumentos de elaboração e sistematização. É daí que surge a importância da escola, que segundo Gramsci deve facilitar o acesso a esses instrumentos.

Pela divisão do trabalho, e com ele do conhecimento, o trabalhador foi expropriado do conjunto da totalidade, ficando-lhe restrito a percepção do conhecimento enquanto produção coletiva. Restando ao trabalhador apenas parcelas, o conjunto passou a pertencer ao setor dominante que se apropriou da sua elaboração enquanto teoria, devolvendo ao trabalhador apenas a parcela relativa à operação que ele vai desenvolver no processo produtivo. Segundo Gramsci na obra "Cadernos do cárcere" (2000, v.2, p. 49), a educação, que nem sempre é feita via escola, deveria ser unitária, desenvolvendo habilidades tanto manuais como intelectuais, afim de superar a dicotomia existente entre o fazer e o pensar. O contato com a técnica não poderia substituir a formação clássica, geral e humanista: "[...] em função da crise profunda da tradição cultural e da concepção da vida e do homem, verifica-se um processo de progressiva degenerescência: as escolas de tipo profissional; isto é, preocupadas em satisfazer interesses práticos imediatos, predominam sobre a escola formativa, imediatamente desinteressada" (GRAMSCI, 2000, p. 49).

A esse respeito, Saviani, na obra "Do Senso Comum à Consciência Filosófica" (2002), destaca a importância fundamental da educação. Como forma de inserção da educação na luta pela hegemonia, Saviani configura dois momentos simultâneos e organicamente harmônicos entre si: o primeiro que consiste na crítica da concepção dominante (a ideologia burguesa); e um segundo momento que se traduz na argumentação das classes populares a fim de dar-lhes expressão elaborada com vistas à formulação de uma concepção de mundo adequada aos interesses populares.

Essa passagem do senso comum à consciência filosófica é condição necessária para situar a educação numa perspectiva revolucionária. Segundo Saviani, é a única maneira de convertê-la em instrumento que possibilite aos membros das camadas populares a organização para uma possível transformação. A grande contribuição de Marx e Engels neste sentido foi a preocupação de indicar o caminho para essa elaboração, o Método Materialismo Histórico, ao levantar na obra "A ideologia Alemã" algumas questões referentes à materialidade das questões teóricas e suas implicações na formação e na compreensão dos processos históricos que as constroem, os autores traçaram um viés que permite a compreensão e crítica da ideologia burguesa e suas implicações no processo educacional. 


\section{CONCLUSÃO}

Na obra Marx, preocupou-se em desmistificar o processo educacional, partindo das relações sociais, tendo o trabalho como elemento de mediação, desvelando as contradições inerentes ao processo de construção da vida pela ótica do capital e de sua influência na produção da mesma. Estabeleceu um novo conceito de homem, partindo da análise da práxis para tecer então uma práxis revolucionária, que segundo ele, deveria começar pela formação do educador. Ao estudar a gênese do capitalismo, e traçar paralelos entre a economia e a organização da vida social, Marx estabeleceu algumas categorias que servem de instrumentos para melhor compreender o momento presente e, permitir ao homem identificar-se como autor e ator histórico.

Ao estabelecer o trabalho, como categoria básica em sua análise desmascarou as contradições e a alienação inerente ao sistema que acentua as desigualdades sociais. Descortinou o processo dinâmico, vivo e sempre sujeito a alterações que pelo trabalho impulsiona transformações históricas nas quais o homem transforma ao mesmo tempo em que é transformado. Ao transformar a forma de produzir a vida pelo trabalho, o homem gesta conceitos, normas e teorias que fundamentem seus atos, o que segundo Saviani, na obra "Escola e Democracia: polêmicas do nosso tempo" (1995) redundam em patrimônio cultural adquirido que the permite exercer domínio sobre outras classes. Desvelar então, o mundo do trabalho é desvelar a própria vida, e compreender como se organizam os homens, permite compreender suas práticas que sempre se embasam em uma teoria de suporte.

Como bem ressalta Pedro Demo em sua obra "Intelectuais e Vivaldinos: da crítica acrítica" (1982), a coerência está em se retirar de uma teoria, uma prática determinada, e não fazer da teorização uma prática suficiente.

E, segundo Arnaldo Niskier (2001), toda fórmula educacional corresponde a uma ideologia e esta sempre estabelece relações de poder, acreditar que não existirá um dia relações de poder seria substituir uma ideologia por outra, mas, o que importa é incentivar a escola a assumir papel não de espectadora acrítica, mas, de incentivá-la a descortinar a seus educandos a possibilidade de conhecer, compreender e assumir suas próprias conclusões a respeito da produção da vida como atores e autores do seu momento histórico. É nesse aspecto que a teoria e a prática se fundem e se completam, no debruçar sobre o processo histórico, reconhecendo-se como sujeitos dele. E nesse sentido, é preciso que os educadores sejam capazes de desvelar as formas de produção material e suas contradições.

\section{REFERÊNCIAS}

DEMO, P. Intelectuais e Vivaldinos: da crítica acrítica. São Paulo: Amed, 1982. p.17-21.

FROMM, E. Conceito marxista de homem. 8. ed. Rio de Janeiro: Zahar, 1983.

GRAMSCl, A. Apontamentos e notas dispersas para um grupo de ensaios sobre a história dos intelectuais. In: Cadernos do Cárcere. Rio de Janeiro: Civilização Brasileira, 2000. v.2, p. 13-53.

MANACORDA, M. A. Marx e a pedagogia Moderna. São Paulo: Cortez, 1991.

MARX, K.; ENGELS, F. A Ideologia Alemã. São Paulo: Moraes, 1984.

NOGUEIRA, M. A. Educação, saber e produção em Marx e Engels. 2. ed. São Paulo: Cortez, 1983.

NIISKIER, A. Marxismo e Educação. In: Filosofia da Educação. Uma visão crítica. São Paulo: Loyola, 2001. cap. XI, p. 175-186. 
SAVIANI, D. Educação: do senso comum à Consciência filosófica. 14. ed. Campinas: Autores Associados, 2002.

. Escola e Democracia. 29. ed. Campinas: Autores associados, 1995.

ados, 2003.

Pedagogia Histórico-crítica: primeiras aproximações. 8. ed. Campinas: Autores Associ-

VÁZQUEZ, A. S. Filosofia da Práxis. Rio de Janeiro: Paz e Terra, 1977. 